\title{
HIV-1 infection among women in Israel, 2010-2018
}

Tali Wagner ${ }^{1,2 \dagger}$, Karen Olshtain-Pops ${ }^{3 \dagger}$, Marina Wax², Olivia Horwitz ${ }^{2}$, Rachel Shirazi ${ }^{2}$, Yael Gozlan ${ }^{2}$, Hadar Volnowitz ${ }^{2}$, Ella Mendelson ${ }^{1,2}$, Itzchak Levy ${ }^{1,4}$ and Orna Mor ${ }^{1,2^{*}}$ (D)

\begin{abstract}
Introduction: Although women comprise 33\% of the HIV-1-carriers in Israel, they have not previously been considered a risk group requiring special attention. Immigration waves from countries in Africa and in East Europe may have changed the local landscape of women diagnosed with HIV-1. Here, we aimed to assess viral and demographic characteristics of HIV-1-positive women identified in Israel between 2010 and 2018.

Methods: All > 16 year-old, HIV-1-infected women, diagnosed in Israel in 2010-2018, $(n=763)$ registered in the National HIV reference laboratory were included in this cross-sectional study. Demographic and clinical characteristics were extracted from the database. Viral subtypes and transmitted drug resistance mutations (TDRM) were determined in 337 (44.2\%) randomly selected samples collected from treatment-naive women.

Results: Median age at diagnosis was 38 years. Most (73.3\%) women were immigrants from the former Soviet Union (FSU) $(41.2 \%, 314)$ or sub-Saharan Africa (SSA) $(32.2 \%, 246)$ and carried subtype A $(79.7 \%)$ or C $(90.3 \%)$, respectively. Only $11.4 \%$ (87) were Israeli-born women. Over the years, the prevalence of women from SSA decreased while that of women from FSU increased significantly $(p<0.001)$. The median CD4 $4^{+}$cell count was 263 cells $/ \mathrm{mm}^{3}$, and higher $\left(391 \mathrm{cell} s / \mathrm{mm}^{3}\right.$ ) in Israeli-born women. TDRM were identified in 10.4\% of the tested samples; 1.8, 3 and $7.1 \%$ had protease inhibitors (PI), nucleotide reverse transcriptase inhibitors (NRTI) and non-nucleoside reverse transcriptase inhibitors (NNRTI) TDRM, respectively. The prevalence of women with NNRTI TDRM significantly increased from 4.9\% in 2010-2012 to 13.3\% in 2016-2018. Israeli-born women had the highest prevalence (16.3\%) of NNRTI TDRM ( $p=0.014)$. NRTI A62 (5.6\%), NNRTI E138 and K103 (5.6 and 4.2\%, respectively) were the most prominent mutated sites.

Conclusions: Most HIV-1-positive women diagnosed in Israel in 2010-2018 were immigrants, with the relative ratio of FSU immigrants increasing in recent years. The high proportion of women diagnosed with resistance mutations, particularly, the yearly increase in the frequency of NNRTI mutations, support the national policy of resistance testing at baseline.
\end{abstract}

Keywords: HIV-1, Women, Resistance-testing, Transmitted drug resistance mutations (TDRM)

\footnotetext{
* Correspondence: orna.mor@sheba.health.gov.il

†Tali Wagner and Karen Olshtain-Pops are these authors contributed equally

to the work and share first authorship.

${ }^{1}$ Sackler Faculty of Medicine, Tel-Aviv University, Tel-Aviv-Yafo, Israel

${ }^{2}$ National HIV and Viral Hepatitis Reference Laboratory, Chaim Sheba Medical

Center, Tel Hashomer, 52621 Ramat Gan, Israel

Full list of author information is available at the end of the article
}

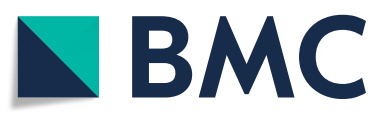

(c) The Author(s). 2020 Open Access This article is licensed under a Creative Commons Attribution 4.0 International License, which permits use, sharing, adaptation, distribution and reproduction in any medium or format, as long as you give appropriate credit to the original author(s) and the source, provide a link to the Creative Commons licence, and indicate if changes were made. The images or other third party material in this article are included in the article's Creative Commons licence, unless indicated otherwise in a credit line to the material. If material is not included in the article's Creative Commons licence and your intended use is not permitted by statutory regulation or exceeds the permitted use, you will need to obtain permission directly from the copyright holder. To view a copy of this licence, visit http://creativecommons.org/licenses/by/4.0/. The Creative Commons Public Domain Dedication waiver (http://creativecommons.org/publicdomain/zero/1.0/) applies to the data made available in this article, unless otherwise stated in a credit line to the data. 


\section{Introduction}

Women comprise more than half (51.2\%) of the 36.7 million people worldwide carrying HIV-1 [1]. However, the proportion of newly infected women varies around the world [2], with the majority (56\%) living in Sub-Saharan Africa (SSA) [2], a region suffering from a generalized HIV-1 epidemic ( $>1 \%$ HIV-1 prevalence) [3]. The second major region with a high proportion of HIV-1positive women (42\%) is Eastern Europe, particularly countries in the Former Soviet Union (FSU), which experienced the fastest growing HIV-1 epidemic in the world [4] between 2003 and 2009, and is currently regarded as a region of concentrated HIV-1 infection [3].

Interventions aiming to reduce the global spread of HIV-1 require understanding modes of HIV-1 transmission, viral subtype distribution and circulation of drugresistant viruses. Viruses harboring drug resistance mutations are a major obstacle to successful HIV treatment, even in the current era of HIV treatment simplification and the shift to dual therapy regimens $[5,6]$. Immigrants from countries with high rates of HIV-1 infection and of viruses with resistance mutations, may be infected and continuously transmit drug-resistant viruses after immigration [7].

Israel is a multicultural country with a continuous influx of immigrants from across the globe. Until 2010, as a result of massive immigration waves, $41.3 \%$ of all HIV cases were immigrants from SSA [8]. Between 2010 and 2018, 174,934 people immigrated to Israel, more than of $50 \%$ of whom were women $[9,10]$. During this period, most immigrants $(59.5 \%, 104,086)[9,10]$ were from the FSU. In comparison, immigrants from SSA [9] constituted only $6.7 \%$ of the total number of immigrants in 2010-2017 (9829/146,835), with a decline from $1918 \mathrm{im}$ migrants in 2010 to 318 in 2017.

Gender is known to be a factor that significantly impacts migration experiences [11]. As a result of economic insecurity, limited education, linguistic and cultural barriers, migrants most often present late to care. These factors may also place migrants, especially women, at risk for acquiring HIV-1 infection [12]. Women immigrating from countries with high rates of HIV-1 infection, unaware of their HIV status, are also at higher risk for delivering infants with perinatally acquired HIV-1 [13], especially as in Israel, where universal HIV-1 prenatal screening is not mandatory [14].

According to the Israeli Ministry of Health, women comprise $33 \%$ of the reported HIV-1-positive individuals [15]. In a report that summarized HIV-1 diagnosis in Israel between 1981 and 2010, most HIV-1-positive women were from countries in Africa, mainly from Ethiopia. Those infected by injecting drugs or through heterosexual transmission comprised only a small minority of the reported cohort [8]. The characteristics of HIV-1 positive women population and the rate of transmitted resistance mutations (TDRM) in women diagnosed in more recent years have not been evaluated. The goal of this study was to profile the demographic and viral characteristics of HIV-1-positive women diagnosed between 2010 and 2018, and to estimate the proportion of women carrying HIV-1 TDRM in Israel.

\section{Methods}

In this cross-sectional study, the database of the $\mathrm{Na}$ tional HIV Reference Center, which has demographic and clinical documentation on all newly diagnosed HIV1 patients in Israel, was screened for women diagnosed between January 2010 and December 2018. Men, transpeople, women below the age of 16 years and women diagnosed in years other than 2010-2018 were excluded. Demographic (age, birth place and route of HIV-1 transmission) and clinical (year of HIV diagnosis, HIV-1 viral load, $\mathrm{CD}^{+}$cell counts, HIV-1 subtype and TDRM) characteristics were collected.

The final cohort included 763 women. As not all treatment-naïve, HIV-1-positive women are routinely tested for resistance, the first available sample collected $<6$ months after initial HIV-1 diagnosis of 337 women (44.2\%), selected each year by a stratified random selection design were analyzed by sequencing of HIV-1 protease (PR, codons 4-99) and reverse transcriptase (RT, codons 38-247). PR and RT TDRM were determined using the World Health Organization (WHO) consensus list of drug resistance mutations updated in 2009 [16] in the HIVdb Program v.8.8 [17]. The polymorphic RTE138 and accessory mutation A62 sites were also assessed. Subtypes were defined by the REGA HIV-1 subtyping tool version 3.0 and Stanford University HIV Drug-Resistance Database [17].

Descriptive statistics was used to assess the study cohort. Variables with non-Gaussian abnormal distribution (assessed by Kolmogorov-Smirnov test) were expressed by median and interquartile range and the Kruskal Wallis test was performed to test the quality of means of several distributions. Categorical variables were expressed by frequencies and compared using chisquared or Fisher's exact test. The Bonferroni method was applied to check whether multiple testing could lead to the risk of type 1 errors. Logistic regression was used to test factors associated with TDRM rates. Multivariable analysis included factors found to be related $(p<$ $0.01)$ to the dependent variable with the forward technique covariate selection and was based on unstandardized effect-size statistics. Potential interactions were controlled by stratification on effect-measure-modifiers to assess heterogeneity of a measure across the levels of another factor. Variables with missing values (e., g 
missing CD4 results) were ignored. Poisson segmented regression (that typically aggregates individual-level data by time points and estimates dynamic changes over time, while adjusting for secular changes [18]) was performed to examine the change in the frequency of HIV TDRM in the study years. Statistical analysis was performed using IBM SPSS statistics version 20.

\section{Results}

Table 1 summarizes the baseline characteristics of HIV1-positive women diagnosed in Israel in the years 20102012, 2013-2015 and 2016-2018. Median age at diagnosis was 38. Main route of HIV transmission $(82.4 \%, n=$ 629) was sexual contact; only $10.9 \%(n=83)$ were injecting drug users (IDUs). Most women were immigrants: $41.2 \%(n=314)$ were born in the FSU, $32.2 \%(n=246)$ in SSA and only $11.4 \%(n=87)$ were born in Israel. While the total number of women identified remained stable over the study period, a significant yearly decline in the proportion of SSA immigrants versus a constant increase in women originating from the FSU was observed $(p<$ 0.001). Similarly, while the overall prevalence of subtype C $(41.8 \%, 141 / 337)$ and A $(38.6 \%, 130 / 337)$ diagnosis was similar, the later years of the study were associated with a decline in the number of subtype $C$ carriers and an increase in the number of subtype A carriers.

A comparison of the characteristics of women born in SSA, FSU, Israel or elsewhere (Table 2) showed that most women from the FSU (79.7\%) were carriers of subtype A, while $90.3 \%$ of those from SSA carried subtype $\mathrm{C}(p<0.001)$. Women were diagnosed with low $(<350$ cells $/ \mathrm{mm}^{*} 3$ ) $\mathrm{CD}^{+}$cell counts (Table 1 ), with lower median counts among women immigrating from SSA and the FSU ( 246 cells $/ \mathrm{mm}^{*} 3$ and 262 cells $/ \mathrm{mm}^{*} 3$, respectively) as compared to Israeli-born women (391 cells/ $\mathrm{mm} * 3, p=0.042$, Table 2).

Resistance analysis revealed that $10.4 \%$ (35/377) of women carried viruses with resistance mutations, with 7.1, 3, and $1.8 \%$ of women carrying NNRTI, NRTI and PI TDRM, respectively. While the proportion of women with NNRTI TDRM increased significantly $(p=0.017)$ between 2010 and 2012 and 2016-2018, paralleling a non-statistically significant increase in the overall prevalence of women with any HIVTDRM diagnosed in these years, the rates of women with NRTI and PI TDRM remained stable. Moreover, in 2016-2018, no women with PI TDRM were identified (Fig. 1). All these results were further corroborated by Poisson segmented regression. No significant difference was observed in the prevalence of women with any TDRM between the different birth-places $(p=0.170)$. Interestingly, the proportion of native Israeli women born in carrying a NNRTI TDRM virus $(16.3 \%, p=0.014)$ was significantly higher compared its prevalence among women born in other countries (Table 2).

Table 1 Characteristics of women diagnosed with HIV, Israel, 2010-2018

\begin{tabular}{|c|c|c|c|c|c|}
\hline & $\begin{array}{l}\text { All years }(2010-2018) \\
N=763\end{array}$ & $\begin{array}{l}2010-2012 \\
N=246\end{array}$ & $\begin{array}{l}2013-2015 \\
N=257\end{array}$ & $\begin{array}{l}2016-2018 \\
N=260\end{array}$ & $p$ value \\
\hline Median age at diagnosis (IQR) & $38(31-46)$ & $37(29-43)$ & $37(30-46)$ & $40(34-48)$ & $<0.001$ \\
\hline \multicolumn{6}{|l|}{ Place of birth, n (\%) } \\
\hline SSA & $246(32.2)$ & $110(44.7)$ & $64(24.9)$ & $72(27.7)$ & \\
\hline FSU & $314(41.2)$ & $77(31.3)$ & $107(41.6)$ & $130(50)$ & \\
\hline Israel & $87(11.4)$ & $30(12.2)$ & $32(12.5)$ & $25(9.6)$ & $<0.001$ \\
\hline Other/Unknown & $116(15.2)$ & $29(11.8)$ & $54(21)$ & $33(12.7)$ & \\
\hline \multicolumn{6}{|l|}{ Risk Groups, n (\%) } \\
\hline Sexual contact & $629(82.4)$ & $202(82.1)$ & $211(82.1)$ & $216(83.1)$ & \\
\hline IDU & $83(10.9)$ & $34(13.8)$ & $33(12.8)$ & $16(6.2)$ & 0.001 \\
\hline Other/Unknown & $51(6.7)$ & $10(4.1)$ & $13(5.1)$ & $28(10.8)$ & \\
\hline HIV-1 Subtype (N) & 337 & 123 & 109 & 105 & \\
\hline A, n (\%) & $130(38.6)$ & 45 (36.6) & $40(36.7)$ & $45(42.9)$ & \\
\hline $\mathrm{B}, \mathrm{n}(\%)$ & $34(10.1)$ & $10(8.1)$ & 17 (15.6) & $7(6.7)$ & \\
\hline $\mathrm{C}, \mathrm{n}(\%)$ & $141(41.8)$ & $61(49.6)$ & $44(40.4)$ & $36(34.3)$ & 0.014 \\
\hline $\mathrm{G} / \mathrm{AG}, \mathrm{n}(\%)$ & $23(6.8)$ & $3(2.4)$ & $7(6.4)$ & $13(12.4)$ & \\
\hline Other, n (\%) & $9(2.7)$ & $4(3.3)$ & $1(0.9)$ & $4(3.8)$ & \\
\hline CD4 (cells/mm*3) $(n=171)$, median (IQR) & $263(121-466)$ & $285(146-496)$ & $270(133-492)$ & $234(73-394)$ & 0.283 \\
\hline VL $(\log \mathrm{c} / \mathrm{mL})(n=236)$, median $(\mathrm{IQR})$ & $4.5(3.9-5.4)$ & $4.4(3.7-5.4)$ & $4.6(4.1-5.2)$ & $4.8(4.3-5.3)$ & 0.519 \\
\hline
\end{tabular}

Data are presented as $\mathrm{n}(\%)$ or median (IQR); IQR Interquartile range, VL Viral load, SSA Sub-Saharan Africa, FSU Former Soviet Union, IDU Injecting drug users. 
Table 2 Characteristics of women diagnosed with HIV in 2010-2018, by place of birth

\begin{tabular}{|c|c|c|c|c|c|}
\hline & SSA & FSU & Israel & Other & $p$ value \\
\hline HIV-1 Subtype $(N=337)$ & $n=124$ & $n=123$ & $n=43$ & $n=47$ & \\
\hline A, n (\%) & $2(1.6)$ & $98(79.7)$ & $14(32.6)$ & $16(34)$ & $<0.001$ \\
\hline C, n (\%) & $112(90.3)$ & $8(6.5)$ & $4(9.3)$ & $17(36.2)$ & \\
\hline Non A, C, n (\%) & $10(8.1)$ & $17(13.8)$ & $25(58.1)$ & $14(29.8)$ & \\
\hline CD4 (cells/ mm*3, $N=159$ ) & $n=52$ & $n=81$ & $n=26$ & No data & \\
\hline Median (IQR) & $246(99-348)$ & $262(106-488)$ & 391 (179-738) & & 0.042 \\
\hline \multicolumn{6}{|l|}{ TDRM by class $(N=337)$} \\
\hline All TDRM, n (\%) & $16(12.9)$ & $10(8.1)$ & $7(16.3)$ & $2(4.3)$ & 0.170 \\
\hline NNRTI, n (\%) & $11(8.9)$ & $6(4.9)$ & $7(16.3)$ & 0 & 0.014 \\
\hline NRTI n (\%) & $5(4)$ & $4(3.3)$ & 0 & $1(2.1)$ & 0.582 \\
\hline
\end{tabular}

Logistic regression was used to assess factors associated with TDRM carriage and carriage of specific TDRMs by drug class. Factors included in this analysis were birthplace (FSU, SSA, Israel or other), HIV-1 subtype (A, $\mathrm{C}$ or non $\mathrm{A} / \mathrm{C}$ ), viral load, age at diagnosis and year of diagnosis (supplemental Table S1). Significant association between recent diagnosis and NNRTI TDRM as found by both univariate (OR: 1.23, 1.05-1.45 of 95\% CI, $p=0.01$ ) and multivariate analysis (OR: $1.23,1.03-$ 1.43 of $95 \% \mathrm{CI}, p=0.020)$. Other associations could not be found.

Table 3 lists the type of TDRMs identified in the study cohort according to drug class. The polymorphic RTE138 and the accessory mutation A62 sites, were also included due to their clinical relevance and high prevalence. A62V which was the most prominent NRTI mutation $(5.6 \%, 19 / 337)$, was significantly more common in HIV-1 subtype A- as compared to HIV-1 subtype Cinfected women $(13 \%, 17 / 130$ versus $1.4 \%, 2 / 141, p<$ $0.001)$. E138 was the most frequently identified mutated NNRTI position $(5.6 \%, 19 / 337)$, detected in $8.5 \%(n=$ $11), 4.3 \%(n=6), 3 \%(n=1)$ and $4.3 \%(n=1)$ of subtype
A, C, B and G/AG carriers, respectively. The NNRTI K103N/S mutation was identified in $4.2 \%(14 / 337)$ of women, and was significantly more prominent in those carrying HIV-1 subtype B compared to those carrying subtype $C(11.8 \%, 4 / 34$ versus $2.1 \%, 3 / 141, p=0.010)$. The most prominent PI mutation was M46I, identified in $1.5 \%(5 / 337)$ of patients.

\section{Discussion}

Analysis of the demographic profiles of women diagnosed with HIV-1 in Israel between the years 2010 and 2018 revealed that most were not born in Israel. In 2010-2012, 44.7\% were immigrants from SSA and 31.3\% were from the FSU. In more recent years (2016-2018), $50 \%$ were from the FSU, while only $27.7 \%$ originated from SSA $(p<0.001)$. The most prevalent viral subtype, changed accordingly, from subtype $C$, characteristic of HIV-1 in SSA, in 2010-2012, to subtype A, characteristic to FSU, in 2016-2018 $(p<0.014)$. These results are in concordance with the waves of immigration from SSA and Eastern Europe to Israel in 2010-2018. A similar increase in the prevalence of subtype A carriers was

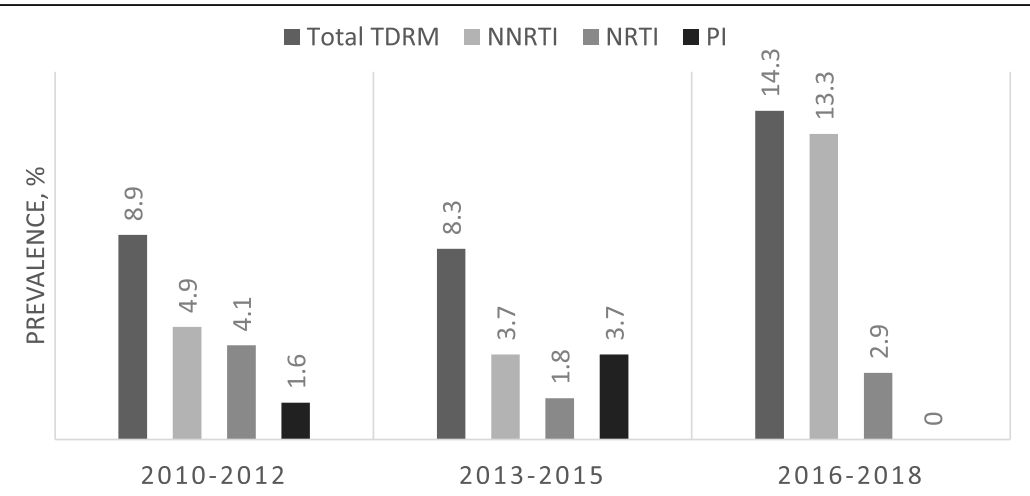

Fig. 1 Prevalence of women diagnosed with HIV-1 TDRM in 2010-2012, 2013-2015 and 2016-2018. Prevalence of women with any TDRM (total) and with NRTI, NNRTI and PI TDRM 
Table 3 Prevalence of most frequently detected TDRM (including NRTI A62 and NNRTI E138) in women, 2010-2018

\begin{tabular}{|c|c|c|c|c|c|c|c|c|c|c|}
\hline \multirow[t]{3}{*}{ Drug Class } & \multirow[t]{3}{*}{ DRM } & \multicolumn{6}{|c|}{ HIV-1 Subtype } & \multirow{3}{*}{$\begin{array}{l}p \text { value } \\
A \text { vs. } C\end{array}$} & \multirow{3}{*}{$\begin{array}{l}p \text { value } \\
B \text { vs. } C\end{array}$} & \multirow{3}{*}{$\begin{array}{l}p \text { value } \\
A \text { vs. } B\end{array}$} \\
\hline & & All & A & $\mathrm{C}$ & B & G/AG & Other & & & \\
\hline & & $N=337$ & $N=130$ & $N=141$ & $N=34$ & $N=23$ & $N=9$ & & & \\
\hline \multirow[t]{3}{*}{ PI, n (\%) } & D30N & $1(0.3)$ & & $1(0.7)$ & & & & & & \\
\hline & M46l & $5(1.5)$ & $1(0.8)$ & $4(2.8)$ & & & & 0.222 & & \\
\hline & V82MS & $1(0.3)$ & & & & $1(1.5)$ & & & & \\
\hline \multirow[t]{7}{*}{ NRTI, n (\%) } & M41L & $1(0.3)$ & & $1(0.7)$ & & & & & & \\
\hline & A62V & $19(5.6)$ & $17(13)$ & $2(1.4)$ & & & & $<0.001$ & & \\
\hline & D67EGN & $5(1.5)$ & $3(2.3)$ & $2(1.4)$ & & & & 0.582 & & \\
\hline & K70R & $3(0.9)$ & $2(1.5)$ & $1(0.7)$ & & & & 0.526 & & \\
\hline & M184V & $5(1.5)$ & $3(2.3)$ & $2(1.4)$ & & & & 0.582 & & \\
\hline & T215EIS & $4(1.2)$ & $1(0.8)$ & $3(2.1)$ & & & & 0.376 & & \\
\hline & K219Q & $1(0.3)$ & $1(0.8)$ & & & & & & & \\
\hline \multirow[t]{7}{*}{ NNRTI, n (\%) } & K101E & $1(0.3)$ & & $1(0.7)$ & & & & & & \\
\hline & K103NS & $14(4.2)$ & $5(3.8)$ & $3(2.1)$ & $4(11.8)$ & $2(8.7)$ & & 0.407 & 0.010 & 0.068 \\
\hline & V106M & $1(0.3)$ & & $1(0.7)$ & & & & & & \\
\hline & E138AGKQ & $19(5.6)$ & $11(8.5)$ & $6(4.3)$ & $1(3)$ & $1(4.3)$ & & 0.156 & 0.731 & 0.276 \\
\hline & Y181C & $5(1.5)$ & $1(0.8)$ & $4(2.8)$ & & & & 0.222 & & \\
\hline & Y188L & $1(0.3)$ & $1(0.8)$ & & & & & & & \\
\hline & G190AS & $6(1.8)$ & $2(1.5)$ & $4(2.8)$ & & & & 0.465 & & \\
\hline
\end{tabular}

Data are presented as $\mathrm{n}(\%)$. Differences in proportions were measured using the chi-squared test. Empty cells, $\mathrm{n}=$ zero.

recently reported in Germany and in other westEuropean countries, due to an increased flow of refugees, mainly from the FSU, into Europe, and especially into Germany [19].

The low CD4 counts noted in this cohort of HIVpositive women, suggest late diagnosis. Moreover, women from SSA, as well as those who immigrated from the FSU, had significantly lower CD4 counts at diagnosis compared to Israeli-born women. Missed opportunities for early diagnosis has already been reported for at least $33 \%$ of the Israeli HIV population [20]. Late diagnosis was also recently reported to characterize over half of the women diagnosed in Europe in 2018 [21]. Our data corroborate these results and highlight the need for improved HIV diagnosis policies targeting new female immigrants. These can include offering HIV testing soon after the arrival of all women immigrating from concentrated and generalized HIV epidemic regions, such as the FSU and SSA, respectively. Also, as most of the women are diagnosed at the reproductive age (median age at diagnosis was 38 years), universal testing for HIV-1 infection during pregnancy should be employed, without limiting it to a selected group, e.g., immigrants from SSA, as is currently performed [22]. It was already demonstrated that a universal approach to perinatal HIV testing achieves the best health outcomes and is cost-effective across a range of HIV-1 prevalence settings [23].
TDRMs were identified in $10.4 \%$ of women diagnosed in the years 2010-2018. Prevalence of women with NNRTI, NRTI and PI TDRMs was 7.1, 3 and $1.8 \%$, respectively. The proportion of women diagnosed with any TDRM and especially with NNRTI TDRMs increased significantly in more recent years, reaching 14.4 and $13.3 \%$, respectively, among women diagnosed in 20162018. In a recent analysis of HIV diagnoses in 2017 in 9 European countries, the overall prevalence of resistance mutations in treatment-naïve patients was $13.5 \%$ and that of NNRTI was 7.7\% [24]. Although these results are similar to our findings in women, they are likely an overestimation of the actual TDRM rate in Europe, as all resistance mutations included in the Stanford HIVdb were considered [16, 17]. In general, changes in prescribing practices over the study period, the high genetic barrier of PI and the lower genetic barrier of NNRTIs, most likely explain the changing rates of drug class-related TDRMs [25]. However, the overall high rate of resistance mutations, the ongoing increase in transmission of resistant viruses, especially in more recent years, and the high rate of individuals on antiviral therapy worldwide, mandates continuous monitoring of pretreatment resistance mutations in Israel and around the world.

NNRTIs are not considered preferred first-line therapies, but are still included in at least some regimens $[5,25]$. In the current study, K103N/S, which confers high-level or intermediate cross-resistance to the NNRTIs efavirenz, 
nevirapine and delavirdine, was the most prominent NNRTI TDRM (4.2\%) and more prevalent in HIV-1 subtype B carriers, as previously reported [26]. As current guidelines permit the use of efavirenz among women of childbearing potential, this rather frequent TDRM should not be disregarded. The polymorphic E138 was the most frequently mutated NNRTI site. This naturally occurring polymorphism that blocks the NNRTI-binding pocket, is known to affect rilpivirine binding and may cause lower susceptibility to this drug [27]. A systematic review that assessed the prevalence of rilpivirine-related TDRMs in 65 countries, already reported an association between E138 mutations and HIV-1 subtypes C (6.1\%), and A (3.3\%) [28]. In the current study, it was identified in $5.6 \%$ of all women, irrespective of the viral subtype. As rilpivirine-based dual therapy is still considered a legitimate treatment option, resistance testing in all patients prior to rilpivirine therapy should be performed. The most prominent NRTI accessory non-polymorphic mutated site was A62V (5.6\% prevalence), which influences replication fidelity and viral fitness in the context of multi-drug resistance mutations [17]. A62V, which was reported to be widespread in subtype A viruses in the FSU [17], was also significantly more prominent in HIV-1 subtype A in the present analysis. However, according to current guidelines, $\mathrm{A} 62 \mathrm{~V}$ does not interfere with therapy.

While there was no significant difference between overall TDRM rates in women originating from different countries, significantly higher NNRTI TDRM rates $(16.3 \%)$ were identified in women born in Israel compared to those born in SSA $(8.9 \%)$ or FSU $(4.9 \%, p=$ $0.014)$. In an earlier study that assessed HIV-positive patients diagnosed between 1999 and 2003 in Israel, resistance mutations were reported in $14.8 \%$ of newly diagnosed, treatment-naïve patients, $28.6 \%$ of whom were known to have been infected in Israel [7]. Together, these results suggest continuous ongoing local circulation of drug-resistant viruses. An in-depth characterization of all HIV-1 patients identified in 20102018 is ongoing.

Our study has several limitations. The main inherent limitation was the overall small number of women positive for HIV diagnosed in Israel. Also, resistance analysis was not performed for all women. However, a stratified selection design was used to selected samples from each year for sequencing and TDRM analysis. However, this study was the first to focus on women diagnosed with HIV in Israel. Women are a subgroup of patients not previously considered a risk group, despite reports on biological sex being an important determinant of risk of HIV infection and of subsequent viral pathogenesis, as well as of treatment responses [29].

\section{Conclusions}

The epidemiology of HIV-1-infected women in Israel is changing, showing a shift toward higher prevalence of women from FSU with subtype A HIV-1, infected through heterosexual contact. The proportion of women with any TDRM exceeded 10\%, a level which, according to $\mathrm{WHO}$, requires resistance testing, especially as the increase in NNRTI rates (13.3\% in 2016-2018) seems to be ongoing. Moreover, when also considering the RT A62 and E138 polymorphic resistance-related sites, as suggested elsewhere $[7,30]$, the overall prevalence of women with drug-resistance mutations increased to $18.4 \%$, an alarming rate of resistance mutations. These results support the national policy of universal resistance testing soon after diagnosis and call for implementation of appropriate measures, including testing all at-risk pregnant women for HIV-1.

\section{Supplementary information}

Supplementary information accompanies this paper at https://doi.org/10. 1186/s12879-020-05389-6.

Additional file 1: Table S1. Predictors of TDRM: univariate and

multivariate models.

\section{Abbreviations}

TDRM: Transmitted drug resistance mutations; FSU): Former Soviet Union; SSA): Sub-Saharan Africa; PI): Protease inhibitors; NRTI): Nucleotide reverse transcriptase inhibitors; NNRTI): Non-nucleoside reverse transcriptase inhibitors; PR): Protease; RT): Reverse transcriptase; IDUs): Injecting drug users; $(\mathrm{QR})$ : Interquartile range; $V \mathrm{~L})$ : Viral load

\section{Acknowledgements}

We would like to thank Mrs. Zehuvit Wiexelboim and Mrs. Zehava Yossefi for their excellent administrative support and for updating and maintaining the Israeli HIV patient database.

\section{Authors' contributions}

OM, TW and KOP designed the study, analyzed the data and drafted the manuscript. MW, OH, RS, YG and HV performed all laboratory analyses. EM and IL contributed to the conceptualization of the manuscript and reviewed it critically. All authors read and approved the final manuscript.

\section{Funding}

None.

Availability of data and materials

The dataset analysed during the current study is available from the corresponding author on reasonable request.

Ethics approval and consent to participate

Ethical approval was obtained by the Helsinki committee of Sheba Medical Center in Israel (5803-18-SMC). Permissions to access the raw data from National HIV Reference Center database were also provided. All data were anonymized and coded as dual-encoding on demand. Consent waiver was obtained for the study.

Consent for publication

Not applicable.

Competing interests

None. 


\section{Author details}

${ }^{1}$ Sackler Faculty of Medicine, Tel-Aviv University, Tel-Aviv-Yafo, Israel. ${ }^{2}$ National HIV and Viral Hepatitis Reference Laboratory, Chaim Sheba Medical Center, Tel Hashomer, 52621 Ramat Gan, Israel. ${ }^{3}$ Hadassah Medical Center, Jerusalem, Israel. ${ }^{4}$ Infectious Disease Unit, Chaim Sheba Medical Center, Ramat Gan, Israel.

Received: 10 May 2020 Accepted: 31 August 2020

Published online: 07 September 2020

\section{References}

1. UNAIDS. Women and girls and HIV: UNAIDS; 2018. [cited 2019 Nov 14]. Available from: https://www.unaids.org/sites/default/files/media_asset/ women_girls_hiv_en.pdf.

2. UN WOMEN. Facts and figures: HIV and AIDS: UN WOMEN; 2018. [cited 2019 Nov 14]. Available from: https://www.unwomen.org/en/what-we-do/hivand-aids/facts-and-figures.

3. Wilson D, Halperin DT. Know your epidemic, know your response: a useful approach, if we get it right. Lancet. 2008;372(9637):423-6.

4. Rechel B. HIV/AIDS in the countries of the former Soviet Union: societal and attitudinal challenges. Cent Eur J Public Health. 2010;18(2):110-5.

5. Boucher CA, Bobkova MR, Hung C-C, Kaiser R, Marcelin A-G, Streinu-Cerce $A$, et al. State of the art in HIV drug resistance: surveillance and regional gaps. AIDS Rev. 2018;20(1):43-57.

6. Casado JL, Monsalvo M, Fontecha M, Vizcarra P, Rodriguez MA, Vivancos MJ, et al. Dolutegravir plus rilpivirine as dual regimen in virologically suppressed HIV-1 infected patients in a clinical setting. HIV Res Clin Pract. 2019;20(2):64-72.

7. Grossman Z, Lorber M, Maayan S, Bar-Yacov N, Levy I, Averbuch D, et al. Drug-resistant HIV infection among drug-naive patients in Israel. Clin Infect Dis. 2005;40(2):294-302.

8. Mor Z, Weinstein R, Grotto I, Levin Y, Chemtob D. Thirty years of HIV in Israel: current epidemiology and future challenges. BMJ Open. 2013;3(7): e003078.

9. Jewish Virtual Library. Total immigration to Israel by select country by year (1948-Present) [Internet]. Jewish Virtual Library. [cited 2019 Nov 14]. Available from: https://www.jewishvirtuallibrary.org/total-immigration-toisrael-by-country-per-year.

10. Central Bureau of Statistics. Immigration to Israel 2018: Central Bureau of Statistics; 2019. [cited 2019 Nov 14]. Available from: https://www.cbs.gov.il/ he/mediarelease/DocLib/2019/206/21_19_206b.pdf.

11. Migration Data Portal. Immigration \& emigration statistics: Migration Data Portal; 2019. [cited 2019 Nov 14]. Available from: https://migrationdataportal. org/themes/gender.

12. Ross J, Cunningham CO, Hanna DB. HIV outcomes among migrants from low-income and middle-income countries living in high-income countries: a review of recent evidence. Curr Opin Infect Dis. 2018;31(1):25-32.

13. Peters H, Thorne C, Tookey PA, Byrne L. National audit of perinatal HIV infections in the UK, 2006-2013: what lessons can be learnt? HIV Med. 2018; 19(4):280-9.

14. Chowers M, Shavit O. Economic evaluation of universal prenatal HIV screening compared with current "at risk" policy in a very low prevalence country. Sex Transm Infect. 2017;93(2):112-7.

15. Ministry of Health Israel. HIV HIV/AIDS in Israel: Periodic Epidemiological Report 1981-2017; 2018. p. 5.

16. Bennett DE, Camacho RJ, Otelea D, Kuritzkes DR, Fleury H, Kiuchi M, et al. Drug resistance mutations for surveillance of transmitted HIV-1 drugresistance: 2009 update. PLoS One. 2009;4(3):e4724.

17. HIVDB. HIV Drug Resistance Database: HIVDB; 2019. [cited 2019 Nov 14]. Available from: https://hivdb.stanford.edu/.

18. Wagner AK, Soumerai SB, Zhang F, Ross-Degnan D. Segmented regression analysis of interrupted time series studies in medication use research. J Clin Pharm Ther. 2002;27(4):299-309.

19. Hanke K, Faria NR, Kühnert D, Yousef KP, Hauser A, Meixenberger K, et al. Reconstruction of the genetic history and the current spread of HIV-1 subtype a in Germany. J Virol. 2019;93(12):e02238-18.

20. Levy I, Maor Y, Mahroum N, Olmer L, Wieder A, Litchevski V, et al. Missed opportunities for earlier diagnosis of HIV in patients who presented with advanced HIV disease: a retrospective cohort study. BMJ Open. 2016;6(11): e012721.

21. Mårdh O, Quinten C, Kuchukhidze G, Seguy N, Dara M, Amato-Gauci AJ, et al. HIV among women in the WHO European Region - epidemiological trends and predictors of late diagnosis, 2009-2018. Euro Surveill. 2019; 24(48):1900696.

22. Mor Z, Pinsker G, Levy C, Haddad E, Levin H, Grotto I. HIV screening for pregnant women in Israel: evaluation of current selective screening recommendations in the light of the local epidemiology. Harefuah. 2013; 152(4):246.

23. Ishikawa N, Dalal S, Johnson C, Hogan DR, Shimbo T, Shaffer N, et al. Should HIV testing for all pregnant women continue? Cost-effectiveness of universal antenatal testing compared to focused approaches across high to very low HIV prevalence settings. J Int AIDS Soc. 2016;19(1):21212.

24. van de Laar MJ, Bosman A, Pharris A, Andersson E, Assoumou L, Ay E, et al. Piloting a surveillance system for HIV drug resistance in the European Union. Euro Surveill. 2019:24(19):1800390.

25. Boucher CA, Bobkova MR, Geretti AM, Hung C-C, Kaiser R, Marcelin A-G, et al. State of the art in HIV drug resistance: science and technology knowledge gap. AIDS Rev. 2018;20(1):27-42.

26. Zuckerman NS, Mor Z, Bucris E, Wax M, Mendelson E, Mor O. Sexual intermingling of Arab and Jewish MSM in Israel: results of a molecular epidemiology study. AIDS. 2019;33(2):339-44.

27. Neogi U, Häggblom A, Singh K, Rogers LC, Rao SD, Amogne W, et al. Factors influencing the efficacy of rilpivirine in HIV-1 subtype C in low- and middle-income countries. J Antimicrob Chemother. 2016:71(2):367-71.

28. Calvez V, Marcelin A-G, Vingerhoets J, Hill A, Hadacek B, Moecklinghoff C. Systematic review to determine the prevalence of transmitted drug resistance mutations to rilpivirine in HIV-infected treatment-naive persons. Antivir Ther (Lond). 2016:21(5):405-12.

29. Griesbeck M, Scully E, Altfeld M. Sex and gender differences in HIVinfection. Clin Sci. 2016;130(16):1435-51.

30. Hofstra LM, Sauvageot N, Albert J, Alexiev I, Garcia F, Struck D, et al. Transmission of HIV drug resistance and the predicted effect on current first-line regimens in Europe. Clin Infect Dis. 2016;62(5):655-63.

\section{Publisher's Note}

Springer Nature remains neutral with regard to jurisdictional claims in published maps and institutional affiliations.
Ready to submit your research? Choose BMC and benefit from:

- fast, convenient online submission

- thorough peer review by experienced researchers in your field

- rapid publication on acceptance

- support for research data, including large and complex data types

- gold Open Access which fosters wider collaboration and increased citations

- maximum visibility for your research: over $100 \mathrm{M}$ website views per year

At $\mathrm{BMC}$, research is always in progress.

Learn more biomedcentral.com/submissions 